\title{
AC 2008-1260: EFFECTIVE USE OF INTEGRATED LECTURE AND LAB TO TEACH CIVIL ENGINEERING MATERIALS
}

\section{Claude Villiers, Florida Gulf Coast University}

CLAUDE VILLIERS is an Assistant Professor of Civil Engineering at Florida Gulf Coast University. He received his Ph.D. in Civil Engineering with a concentration in Materials and Construction from the University of Florida in 2004. Previously Dr. Villiers was an Assistant Professor at The City College of New York. Prior to this position, he was employed by the Florida Department of Transportation (FDOT) as a research engineer. Dr. Villiers also was employed by The University of Florida and worked on several projects sponsored by the FDOT and the Federal Highway Administration.

\section{Yusuf Mehta, Rowan University}

Dr. Mehta is an Associate Professor at the Department of Civil and Environmental Engineering at Rowan University. His research and teaching interests include pavement materials and design, service learning, and transportation safety. Dr. Mehta has published several technical and educational papers in leading professional organizations.

\section{Robert O'Neill, Florida Gulf Coast University}

Robert J. O'Neill is Professor and Chair of the Department of Environmental and Civil Engineering in the U.A. Whitaker School of Engineering at Florida Gulf Coast University. He received his Ph.D. in Structural Engineering from Kansas State University in 1993, M.S. degrees in Structural and Geotechnical Engineering from Stanford University in 1984, and a Bachelor of Science from the United States Military Academy at West Point in 1975. He served in the Army Corps of Engineers for 23 years and retired as a Lieutenant Colonel. Dr. O'Neill has been active as a Senior Mentor and instructor in Project ExCEEd for the American Society for Civil Engineering. 


\title{
Effective Use of Integrated Lecture and Lab to Teach Civil Engineering Materials
}

\begin{abstract}
The civil engineering (CE) materials course along with the other courses in the U.A. Whitaker School of Engineering (WSOE) at Florida Gulf Coast University (FGCU) is taught in an integrated lecture lab style. In this non-traditional setting, instructors use an integrated, active, and collaborative instructional technique. Also, unlike many other universities, there is not a separate time slot allocated in the schedule to conduct the laboratory experiments for this $\mathrm{CE}$ materials course. Instead, the lab is embedded into the course structure. Although it has been documented in the literature that this technique represents effective teaching pedagogy only a few engineering programs have adopted this method. In addition, the WSOE is only in its third year since students were first admitted into the engineering program as freshman. The CE materials course, which is taught to juniors, was offered for the first time this year. To ensure that student learning is maintained, the authors used a comparative approach with a CE instructor at Rowan University. Both instructors, one at FGCU and one at Rowan, used a similar syllabus, test structure and content, and student laboratory report assignments in their classes.

Furthermore, a lecture from FGCU was recorded and viewed at Rowan to determine how other students reacted to the new technique. One laboratory report, which was graded by both instructors, was selected along with a student survey and selected assignments to assess the effectiveness of the new technique in the CE materials course at FGCU. The information presented in this paper could be used as an evaluation benchmark for other courses in the engineering program at FGCU. Also, schools in primarily teaching institutions could use the lecture lab technique to increase student participation and improve student learning in engineering courses.
\end{abstract}

\section{Introduction}

Florida Gulf Coast University (FGCU) is the newest public university in Florida. Established in 1997, FGCU attracts thousands of new freshmen each year because of its commitment to academic excellence combined with a growing, younger regional population. The U.A. Whitaker School of Engineering which first admitted students in 2006, has debuted with three majors leading towards the Bachelor of Science degrees in Bioengineering, Civil Engineering, and Environmental Engineering. The teaching mission of FGCU and the U.A. Whitaker School of Engineering is to foster excellence in teaching by incorporating innovation including integrated lecture lab style methods in all the engineering classes.

The Civil Engineering Materials course was offered for the first time to a group of 21 students. Conventionally, students enrolled in a CE Materials course also register for a separate lab section to conduct laboratory experiments. That is not the case at FGCU; instead, the lab is embedded into the course structure. The materials were presented in an integrated lecture/lab format throughout the course. Proponents of this teaching pedagogy believe that student engagement and enthusiasm is increased and student learning improves significantly ${ }^{1}$. 
In this paper the authors describe the way integrated lecture lab is perceived in the WSOE at FGCU. The effectiveness of this teaching pedagogy was evaluated based on a student survey conducted at the end of the CE Materials course. The survey was structured so that the student could assess the class materials as a whole, assess the student learning, and rate the teacher performance based on the new technique. Outside feedback from faculty at Rowan University on how other their students reacted to this new technique was also considered.

\section{Course Structure and Outline}

The Civil Engineering program is in its third year in the U.A. Whitaker School of Engineering at Florida Gulf Coast University. Upper level courses are now offered to the first cohort of students matriculated into the program. The Civil Engineering Materials course was offered for the first time in the fall of 2007 to 21 students. The authors are well experienced in teaching this course. One of the authors, currently at FGCU, taught this course at other institutions including The City College of The University of New York. The other author taught this course for the $5^{\text {th }}$ consecutive year at Rowan University. Similarly to FGCU, Rowan and CCNY admit most of their students within the local geographic regions. All three schools can be classified as small to midsize universities with enrollment from about 10,000 to 15,000 students.

At FGCU, this course was designed for undergraduate students in the Civil Engineering department. The objectives were:

- To identify and describe the physical, mechanical, and other important properties of the major civil engineering materials used including aggregates, asphalt binder, hot-mix asphalt, cement, concrete, wood, metals, plastic, and composite materials,

- To identify the relevant specifications and standards for these materials and to conduct relevant laboratory tests on almost all these materials,

- To design asphalt concrete and Portland concrete cement mixtures, grade asphalt binder, and evaluate the behavior of these materials and their effect on performance, and

- To develop effective lab report preparation and writing skills.

On an average, an additional hour is added in the integrated lecture lab format as compared to the conventional approach. For example, this CE Materials course was structured in two 21/4 hours per week. Normally for a three hour credit hour, the lecture time is about 3 hours. However, in the conventional system for courses with laboratory requirements such as this CE material, an additional hour or two is allocated to conduct the laboratory tests. However, the lab is normally instructed by graduate students.

Due to the fact that this new approach of lecture lab style requires additional time and effort of preparation, to balance the faculty teaching load the WSOE administrators treat this three credit hours course to four contact hours. The course outline along with topics covered is presented in Table 1. These topics are typical to Civil Engineering Materials course in different institutions. In fact, the syllabus is very similar to the one at Rowan University. Details about each modules including aggregate, cement, PCC, liquid asphalt, HMA, and wood were presented by Mehta ${ }^{2}$. As presented in the table, in addition to the lecture lab format, four separate labs were conducted outside the classroom environment. As in the conventional approach, these lab exercises were carried out in a typical laboratory environment. In addition, two field trips were conducted 
visiting HMA and PCC plants, respectively. These labs and field trips were scheduled and were counted as part of the lecture time.

Table 1. Course outline and topics covered

\begin{tabular}{|c|c|c|c|}
\hline Date & Week & Topic (Lecture/Lab) & Reference \\
\hline Aug. 20 & \multirow{2}{*}{1} & Properties of Engineering Materials & \multirow{3}{*}{ Lecture Notes } \\
\hline Aug. 22 & & Material variability & \\
\hline Aug. 27 - Sept. 5 & 2 & Aggregate & \\
\hline Sept. 10 & 3 & Lab No. 1 test on aggregates & Lab. Notes \\
\hline Sept. 12 - Sept. 17 & 3,4 & Portland cement & Lecture Notes \\
\hline Sept. 19 & 4 & Exam $1-$ Up to aggregates & \\
\hline Sept. 24 - Oct. 1 & \multirow[t]{2}{*}{5,6} & Concrete mix design & Lecture Notes \\
\hline Oct. 3 & & Field trip and lab on cement and PCC & Lab. Notes \\
\hline Oct. 8 & \multirow{2}{*}{7} & Introduction to asphalts - PCC lab report is due & \multirow{4}{*}{ Lecture Notes } \\
\hline Oct. 10 & & Grading of asphalt cements & \\
\hline Oct. 15 & \multirow[t]{2}{*}{8,9} & Exam $2-$ Up to cement and PCC & \\
\hline Oct. $17-24$ & & HMA mix design procedures & \\
\hline Oct. 29 & \multirow{2}{*}{10} & Lab on HMA & \multirow{2}{*}{ Lab. Notes } \\
\hline Oct. 31 & & Field trip to HMA lab & \\
\hline Nov. 5 & \multirow[t]{2}{*}{11,12} & Recycling of asphalt pavement materials & \multirow{2}{*}{ Lecture Notes } \\
\hline Nov. 7,14 & & Timber & \\
\hline Nov. 19 & \multirow[t]{2}{*}{13} & Exam 3 - Up to HMA mix design & \\
\hline Nov. 26 & & Lab No. $4-$ Test on timber & Lab. Notes \\
\hline Nov. 28 & \multirow[t]{2}{*}{14} & Composite materials wood lab report is due & \multirow{2}{*}{ Lecture Notes } \\
\hline Dec. 3 & & Special materials & \\
\hline Dec. 10 & & Final & \\
\hline
\end{tabular}

\section{Grading and policy}

Homework was assigned periodically and weighted $10 \%$. There were several pop quizzes throughout the semester worth $15 \%$ of the entire grade. They were also four tests and four laboratory reports (one for each module) that counted for $60 \%$ of the final grade. The cumulative final counted for $15 \%$ of the total grade. No make-up quizzes and tests were given without prior authorization or accordance to the university policy. It was mandatory that students were present during the laboratory tests, unless the absence was approved by the instructor in advance.

\section{Analysis and Results}

At the end of the semester, a survey was conducted to determine the student perspective on the integrated lecture lab style. The survey was also designed to determine the effectiveness of the use of the new approach, assess the student learning, and rank the instructor performance level. A copy of the survey is provided in Table 2. Inferences will be made using the results from the survey. In addition, feedback was given by faculty at Rowan University on the course outline and content, tests structure and content, and student laboratory reports. Furthermore, a lecture 
from FGCU was recorded and viewed at Rowan University to determine the effectiveness of this new technique.

Table 2. Questions used in student evaluations to evaluate the integrated lecture lab, class content, and instructor

\begin{tabular}{|l|l|}
\hline Scale: & $\begin{array}{l}\text { Strongly Agree (SA); Agree (A); Neutral (N); Disagree (D); Strongly Disagree (SD); } \\
\text { Not Applicable (N/A) } \\
\text { Excellent (E); Good (G); Adequate (A); Poor (P); Very Poor (VP); Not Applicable (NA) }\end{array}$ \\
\hline Q-1 & Do you feel that the integrated lecture lab style was effectively used by the instructor \\
\hline Q-2 & $\begin{array}{l}\text { Do you feel that the use of the lecture lab technique increases student participation and } \\
\text { improve student learning in this Materials Course? }\end{array}$ \\
\hline Q-3 & In the future, this course should structure with separate lecture/lab format? \\
\hline Q-4 & Did the tours advanced my learning in the materials? \\
\hline Q-5 & Did the lab reports improve your learning in this course? \\
\hline Q-6 & Did newly designed rubric help you in preparing the lab reports? \\
\hline Q-7 & $\begin{array}{l}\text { Were the teaching materials (class/lab notes, CD, Web Based interactive product ...) } \\
\text { very helpful? }\end{array}$ \\
\hline Q-8 & Did the teacher stimulate interest and enthusiasm in the subject? \\
\hline Q-9 & Did the teacher stimulate intellectual curiosity? \\
\hline Q-10 & Did the teacher display enthusiasm for teaching? \\
\hline Q-11 & Did the teacher structure the subject content in ways which assisted learning? \\
\hline Q-12 & Overall, did the structure of this class improve your learning in this course? \\
\hline Q-13 & How would I rate the instructor for this class? \\
\hline
\end{tabular}

\section{Integrated Lecture Lab}

The idea behind the integrated lecture lab technique is to create a hands-on atmosphere in the classroom environment. As the instructor presented new concepts, he/she may have used actual equipment or materials to create a real time connection between the students and the topic/subject in question. The students then separated into small groups for hands-on, problem solving sessions, or group discussions.

The integrated lecture lab format was attempted as much as possible throughout the semester. The students who were registered for the CE Materials were accustomed to this format in previous courses including Statics and Strength of Materials in the WSOE at FGCU. Since this technique is fairly new, especially for engineering courses, there was not a ready set of equipment or setup that could be found commercially to teach this CE Materials course. Sources of commercially available equipment and vendors were supplied by O'Neill et al. for other courses such as Statics and Strength of Materials ${ }^{3}$. In this CE Materials the instructor customized a suite of existing equipment to incorporate the integrated aspect of this course.

Figures $1-3$ represent a sample of one of the lectures that was conducted using the integrated lecture lab style. The purpose of this lecture was to describe and characterize the physical properties of aggregates including particle shape and surface texture of aggregate using test procedures and guidelines to design a Hot Mix Asphalt (HMA) mixture. The test procedures used in this lecture are those recommended by the SuperPave mix design criteria which include 
coarse aggregate angularity (CAA), fine aggregate angularity (FAA), and flat and elongated particles. Figure 1 was a photograph that was taken during this sample lecture while the instructor was explaining the subject to the students. The instructor used various media including real equipment, images and/or pictures in a PowerPoint presentation as part of the integrated lecture lab style. After 15 to 20 minutes of lecturing, the students were grouped into five to six students (depending on the number of stations) to conduct the appropriate tests procedures, record and analyze the data, and discuss the test results among themselves (Figure 2). If time allowed, a student from each group was selected to discuss the test results and significance to the entire class (Figure 3). Under the conventional approach, such lectures would have been discussed in class and later carried out in the form of laboratory experiment. In some universities, these laboratory experiments or problem solving session are taught by student assistants. At FGCU everything is administrated and taught by the instructor. In addition, many classes that used the integrated lecture lab met for one additional hour as compared to the conventional method. As a result, an additional contact time is added in all the engineering courses at FGCU to balance the faculty teaching load.
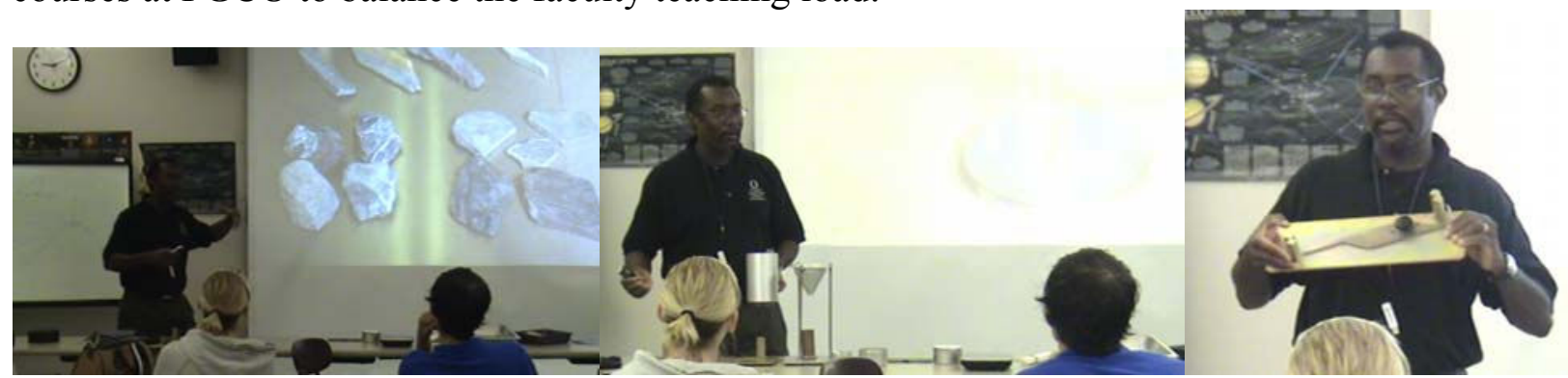

Figure 1. Instructor discussing coarse aggregate angularity, fine aggregate angularity, and flat and elongated particles test procedures, respectively.

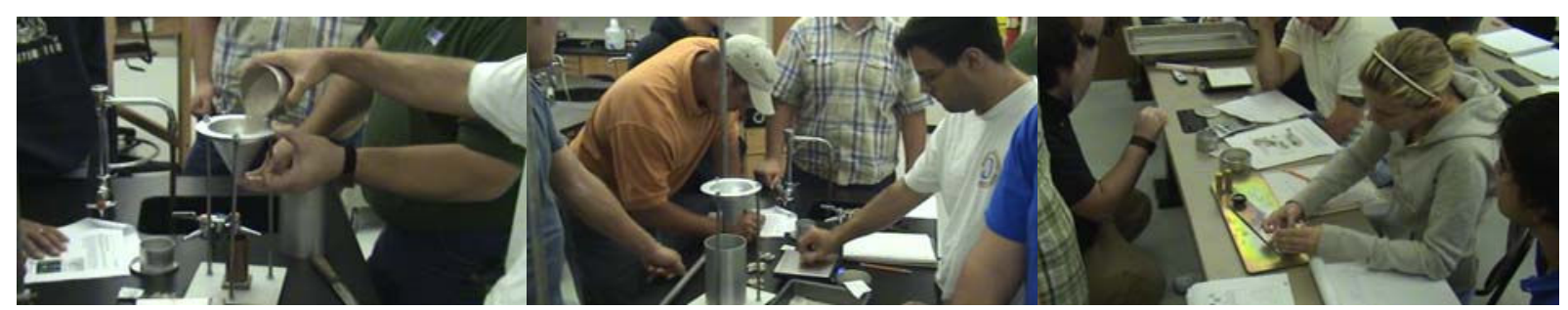

Figure 2. Students conducting test procedures, recording test data, and discussing test results among the group, respectively.

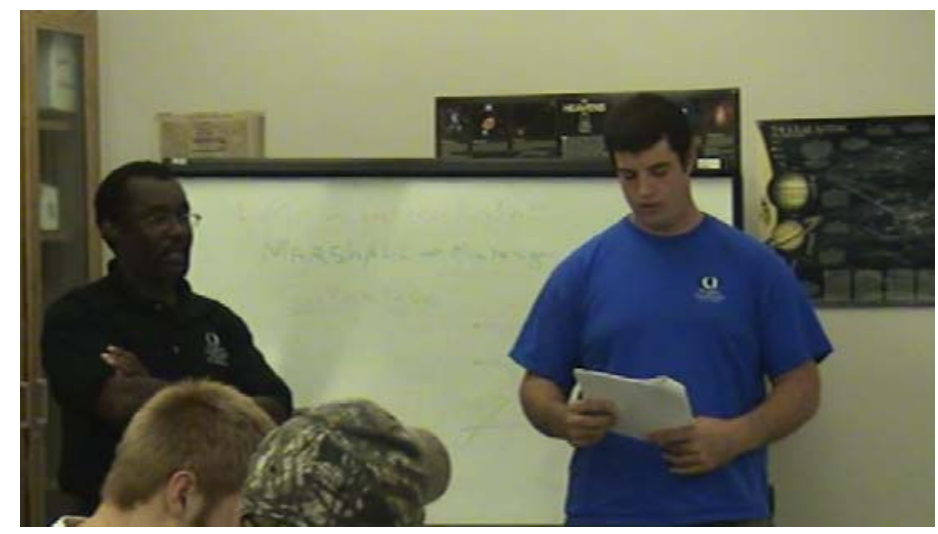

Figure 3. Students reporting and discussing test results tot the entire class. 


\section{Student Perspective on the Integrated Lecture Lab}

While this technique is not new, it appears that this style of teaching creates a direct connection between the students and the subject matter. It is also believed that students will be more likely to engage in discussions, retain what they've learned, and have a lasting interest in the topic. This is supported by the response from the survey taken at the end of the semester. The results for the first 3 questions (see Table 1), were graphically presented in the Figure 4. The survey was distributed to all 18 students who attended class that day. However, for unknown reasons, five students did not participate in the survey. Based on the information that is presented in Figure 4, $77 \%$ of the students felt that the integrated lecture lab style was effectively used by the instructor. Also, 77\% also believed that lecture lab technique increases student participation and improves student learning in this CE Materials course; $8 \%$ voiced no opinion; and $15 \%$ disagreed. This is in agreement with previous courses including Statics and Strength of Materials in the department. In the comment section, the students (for the most part) reported that the group experiment and problem solving got everyone involved and helped with the understanding of the subject matter.

However, they were divided on the strictly teach this course on only integrated lab format. Half of the students still preferred separate lecture and lab format (Figure 4 question 3). It must be noted that four separate labs were conducted in a typical laboratory setting outside the classroom environment. These labs which include full testing on aggregate, wood, HMA and PCC mix design were fairly lengthy and time consuming. The authors share the same opinion of the students who believed that it would be a challenge to break these laboratory exercises into small components to implement the integrated lecture lab series. The engineering building at FGCU that is now under construction was designed with classrooms side by side with the laboratory. This was part of the planning decision during the design phase of the building to support the integrated lecture lab format in the WSOE at FGCU. Perhaps with the completion of the building such assignments could be attempted. In addition, integrated lecture lab does not eliminate the conventional format "long lab", especially when deemed necessary. Instead it promotes a direct connection between the lecture and the laboratory experiment at all times possible.

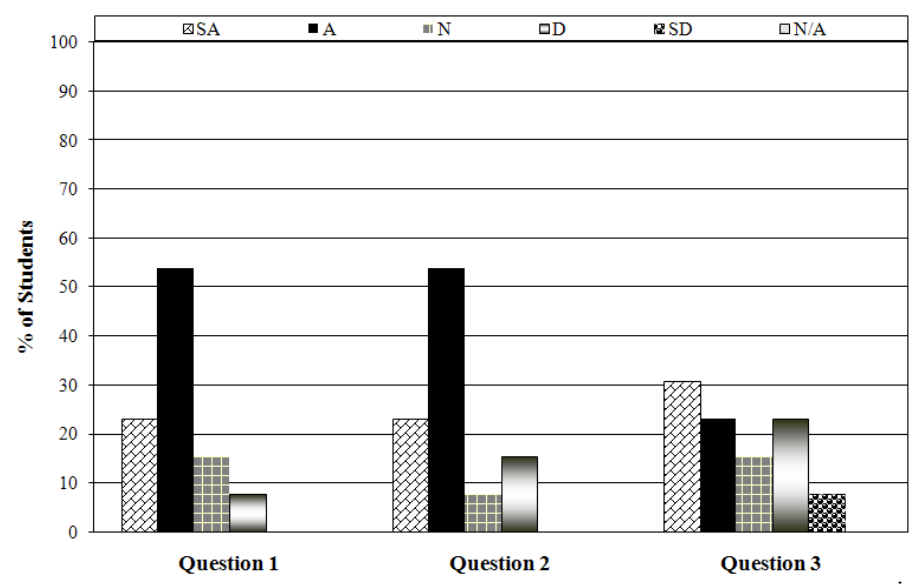

Figure 4. Student's perspective of integrated lab (IL) ${ }^{\mathrm{i}}$

${ }^{\mathrm{i}} \mathrm{Q} 1$ - effectiveness of IL, Q2 - IL relationship to student participation and learning, Q 3 -IL versus separate lecture/lab 


\section{Laboratory experiment and tours}

As part of the integrated lab lecture format, the students conducted four laboratory experiments at typical laboratory settings. Given that these labs were lengthy and time consuming and since this CE Materials class is offered for the first time, the instructor felt that these four laboratory experiments should have been conducted using the conventional setting. In addition, the engineering building at FGCU is still under construction. Perhaps in the future these labs could be attempted using the integrated lab format.

The laboratory experiments conducted include a suite of testing on aggregates (gradation, coarse and fine aggregate specific gravity, and absorption), a full mix design on HMA and PCC, and physical properties characteristic and performance on wood. The objectives of these laboratory experiments were identical to those used by Mehta ${ }^{2}$. Two field trips were also scheduled during the semester. The students visited the APAC HMA Plant and Cemex PCC plants in Naples, Florida. During the visits, the students were exposed to real life experience and learned from world class experts in the field. Both companies were very supportive. This interaction was, indeed, a tremendous opportunity for the young engineering program at FGCU.

The students wrote a laboratory report for each of the four laboratory exercises. The aggregate and HMA labs were reported individually; whereas, the instructor permitted group reports for the PCC and wood modules. The new design report rubric that was produced by the engineering faculty in the WSOE was made available to the students to facilitate them while they were writing their reports. The reports were also graded using the rubric. The students strongly (over $90 \%$ ) supported the fact that the tours and lab reports advanced and improved their learning in the materials (see Figure 5). However, they were divided on the use of the newly designed rubric as a tool in preparing the lab reports. This mixed result indicated that improvement needs to be made in the rubric. Perhaps not enough was done by the instructor to explain to the students the importance of the rubric and its value in preparing the reports.

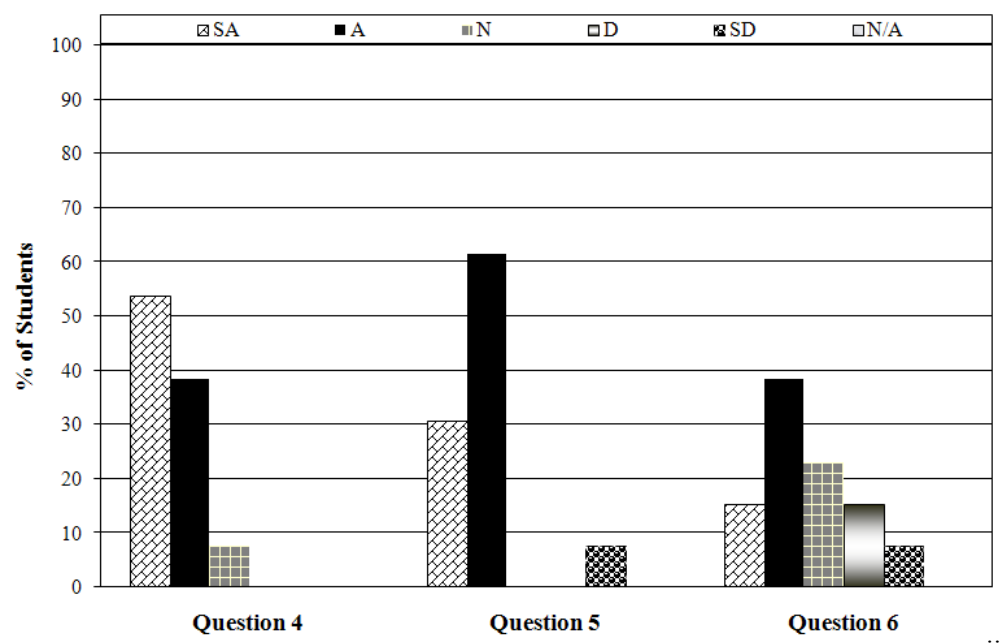

Figure 5. Student's perspective of the lab reports and tours ${ }^{\mathrm{ii}}$

\footnotetext{
${ }^{\mathrm{ii}} \mathrm{Q} 4$ - tours, Q5 - IL lab reports, Q 6 - Did newly designed rubric helped you in preparing the lab reports?
} 


\section{Learning Level and Instructor Performance Rating}

Teaching quality and student learning are difficult to measure quantitatively. In the survey (see Table 1), questions $7-13$ were designed in an attempt to determine the effectiveness of the teaching materials, measure students' learning, and rank the instructor's performance level in the course. Additional feedback would be provided later by the faculty at Rowan University. The results from the survey are presented in Figure 7. The level at which the students rank the instructor's performance is presented in Figure 8. Based on the information that was reported by the students, they learned a great deal based on the materials that were presented in this course. They also reported that the instructor was enthusiastic which is important in any form of pedagogy selected by an instructor. As mentioned by Estes ${ }^{4}$ and Villiers ${ }^{5}$, a professor should be energetic, enthusiastic, encourage positive rapport and more importantly demonstrate good knowledge and a clear explanation of the subject matter to simulate student learning in any style of teaching. The students gave high marks on the overall assessment and instructor ratings. Over $90 \%$ of the students agreed that the class was well instructed which improved their learning on the subject matter. The instructor believes that improvement needs to be made in the way the subject content was structured to assist in student learning (Question 11). Certainly with more experience and time, a better culture may be developed between the students and the faculty. One of the students added in the comment section of the survey that "It is completely normal to have weaknesses on the first time teaching a class. However, it will get better with time". The student added that "I have no doubts about your knowledge on the subject matter". Also the students were accustomed to more time allocated for group problem solving in previous classes that used integrated lecture lab format. Other aspects such as better organization, promptness on grading and making the solutions problems available would also help student learning.

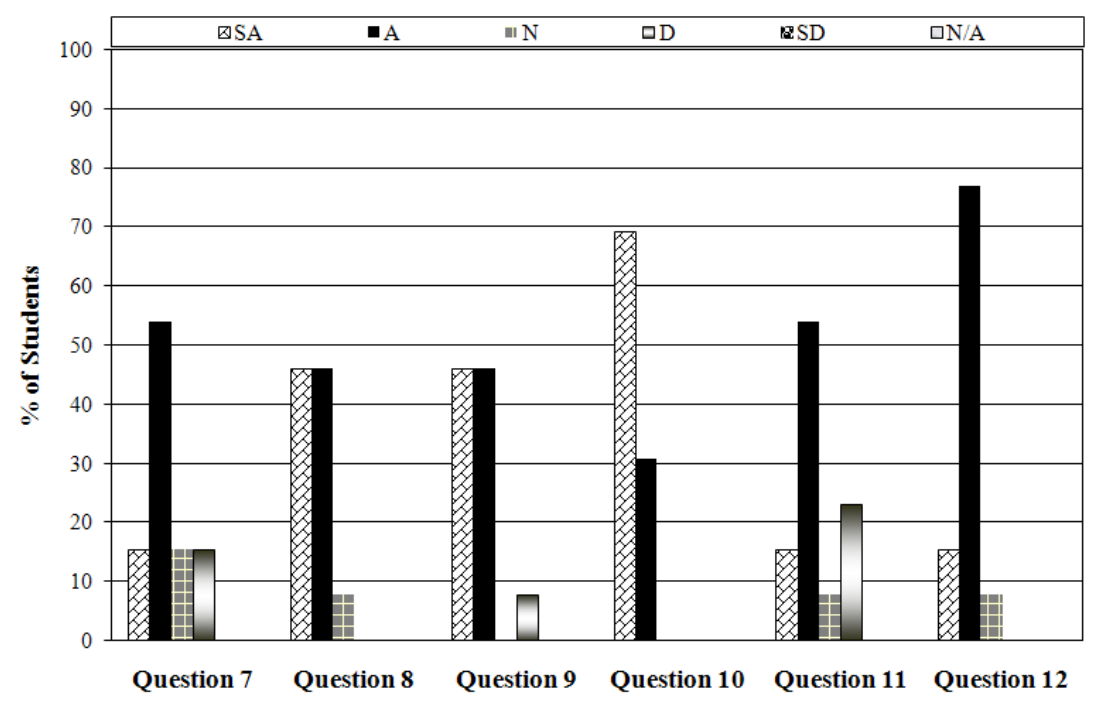

Figure 7. Quality of the teaching materials and assessment of student learning level ${ }^{\mathrm{iii}}$

\footnotetext{
iii Q7 - Were the teaching materials helpful? Q8 teacher stimulate interest and enthusiasm; Q9 teacher stimulate intellectual curiosity; Q10 teacher display enthusiasm for teaching; Q11 Did the teacher structure the subject content in ways which assisted learning? Q12 Overall, did the structure of this class improve your learning in this course?
} 


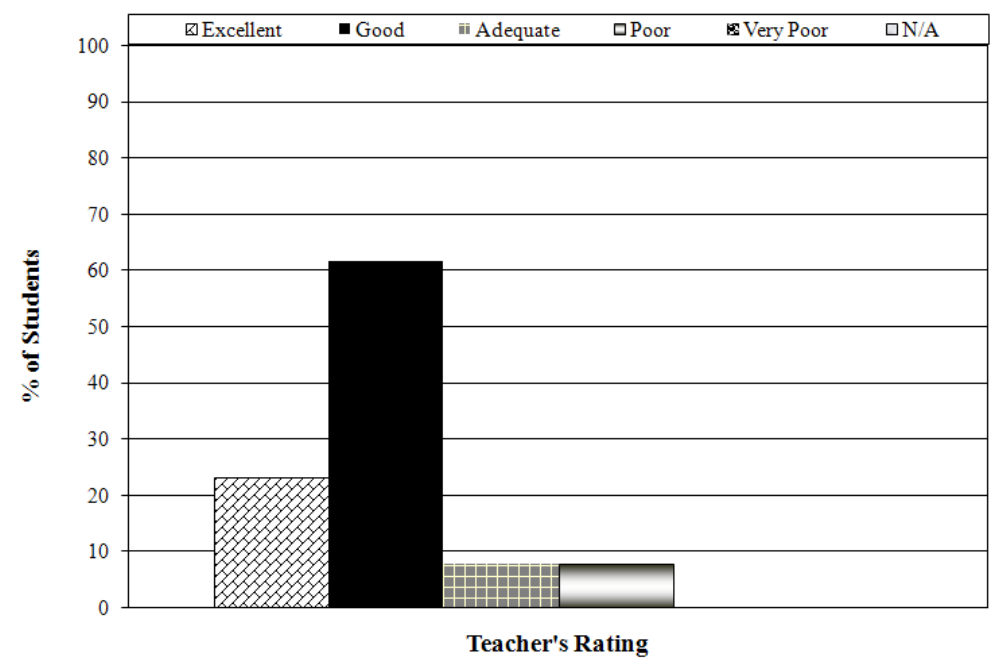

Figure 8. Instructor's performance rating

\section{Feedback from a Faculty at a Different Institution}

A faculty member at Rowan University was consulted from the very beginning of the course to give feedback about the new technique from an outside viewpoint. In order to compare the students from both institutions on the same basis, a three-question "quiz" was taken by the students in both schools on the first day of class. The quiz was well designed based on the following objectives:

- Compare the student knowledge on the Strength of Materials course, which was a prerequisite for this $\mathrm{CE}$ Materials course.

- Compare the student knowledge on the materials that would be covered in the $\mathrm{CE}$ Materials.

Results from this exercise demonstrated the student background was comparable. As was expected, the students did not have extensive knowledge on the CE Materials. There was a trick question in which the students would make the same systematic errors unless they had previous exposure to some concepts that would be covered in the CE Materials course. One student from Rowan answered the question right. Perhaps this student was repeating the course; this made sense given that this course was offered for the first time at FGCU.

This exercise was important to give the faculty at Rowan an idea of the FGCU students' background knowledge who were enrolled in the CE materials. Knowing the students from both schools had similar backgrounds, the faculty were able to evaluate the new format on the same basis. Both instructors used a similar syllabus, test structure and content, and student laboratory report assignments in their classes. A lecture from FGCU was recorded and viewed at Rowan to determine how other students would react to the new technique.

Based on the information received, the faculty at Rowan agreed with the FGCU faculty that if the integrated lecture lab is structured and executed properly, it could be an effective approach to stimulate engineering students interest and enthusiasm on engineering courses. The faculty concurred that students will react positively, using this new technique. Students will be more 
confident as they solve problems or run tests with the material from the lecture fresh in their minds. In addition, they have the opportunity to ask questions to the faculty as the lecture, problem solving session, and/or test experiment unfold. In addition, if proved effective, such an approach may help in student retention and recruitment. However, there are pitfalls associated with the method. One has to be careful in creating a balance for students with differences in learning ability. Also, it is hard to envision this approach in every course within an engineering discipline. Again, there is no doubt that the integrated lecture lab format has excellent components that are worth evaluating. Plans are on the way for next fall to use the integrated lecture lab format in some selected lectures at Rowan to evaluate how students from different institutions will react to this new approach.

\section{Conclusion}

In this paper the authors describe the integrated lecture lab method as envisioned in the WSOE at FGCU. This is very limited data; therefore, no true conclusions can be made. However, based on a survey that was taken at the end of a CE Materials it appears that engineering students at FGCU believe this new style of teaching creates a direct connection between students and the subject matter. The author believes that students will be more likely to engage in discussions, retain the materials, and have a better enthusiasm for the topics presented. As a result, student learning will increase. These views were shared by Rowan faculty who reviewed the materials from this course. Schools in primarily teaching institutions could benefit by using the lecture lab technique to increase student participation and improve student learning in engineering courses. However more data is needed to fully validate this approach.

\section{Acknowledgements}

The authors would like to acknowledge with gratitude the support of the engineering faculty at the U.A. Whitaker School of Engineering School of Engineering.

\section{Bibliography}

1. Smith, K.A., Sheppard, S.D., Johnson, D.W., and Johnson R.T. "Pedagogies of engagement: Classroom-based practices," Journal of Engineering Education, Vol. 94, pp. 87-101, 2005.

2. Mehta, Y. "Innovative techniques to teach civil engineering materials laboratory," Proceedings of the 2004 ASEE Annual Conference and Exposition, June, 2004.

3. O'Neill, R., Geiger, C., Csavina, K., Orndoff, C. "Making statics dynamic!” Combining lecture and lagoratory into an interdisciplinary, problem-based, active learning environment". Proceedings of the 2007 ASEE Annual Conference and Exposition, June, 2007.

4. $\quad$ Estes, A., Welch, R., and Ressler, S. Teaching lessons learned: The ExCEED Teaching Model. Journal of Professional Issues in Engineering Education Practice, Volume 131, No. 4, pp. pp. 218-221, October 2005.

5. Villiers, C. "Adhere to your Style but be Flexible while Transitioning from One Institution to Another: A Case Study in Assessment Teaching Style." Proceedings of the 2007 ASEE Annual Conference and Exposition, June, 2007. 